\title{
Epidemiology of pediatric sepsis in the pediatric intensive care unit of king Abdulaziz Medical City, Jeddah, Saudi Arabia
}

Mohamed O. Humoodi ',2, Mona A. Aldabbagh ${ }^{1,2,3}$, Maher M. Salem ${ }^{1,2}$, Yousef M. Al Talhi ${ }^{2,3^{*}}$, Sara M. Osman ${ }^{1,2}$, Mohammed Bakhsh ${ }^{1,2,3}$, Abdullah M. Alzahrani ${ }^{1,2,3}$ and Maha Azzam ${ }^{1,2,3}$

\begin{abstract}
Background: Pediatric sepsis remains a significant cause of morbidity and mortality worldwide. This study aimed to identify the incidence of sepsis and septic shock among patients admitted to the pediatric intensive care unit (PICU) of a tertiary center in Saudi Arabia. Patients' demographics and risk factors associated with sepsis-related mortality were also investigated.

Methods: A retrospective cohort study was conducted in the PICU of King Abdulaziz Medical City, Jeddah (KAMCJ). KAMC-J is a tertiary care hospital in the western region of Saudi Arabia. A total of 2389 patients admitted to the PICU of KAMC-J between January 1, 2013 and December 31, 2017 were screened and evaluated for sepsis using The Third International Consensus Definitions for Sepsis and Septic Shock (Sepsis-3).

Results: Of the 2389 total admissions to the PICU, 113 patients (4.9\%) met the definition of Sepsis-3; 50.4\% of the 113 patients met the definition of septic shock. Most patients (66.3\%) were less than 6 years old, and $52.2 \%$ were male. Eight-five patients (75.2\%) had underlying comorbidities. The respiratory system was the most common primary site of infection (57.5\%). Bacterial and viral infections were the most common infectious etiology with reported rates of 29.2 and $21.2 \%$, respectively. The median duration of PICU stay was 8 days and the 28-day PICU mortality rate was 23.9\%. A Pediatric Sequential Organ Failure Assessment (pSOFA) Score greater than four and a pre-existing percutaneous central venous catheter were associated with a significant increase in mortality, with adjusted odds ratios of 3.6 (95\% confidence interval: 1.30-9.93) and 9.27 (95\% confidence interval: 1.28-67.29), respectively.
\end{abstract}

Conclusions: The incidence of sepsis in our institution is comparable to that reported internationally; however, the mortality rate is higher than that of developed countries. Nationwide studies identifying sepsis epidemiology are needed to improve the outcome of pediatric sepsis. Following international guidelines for central-line insertion and maintenance is of paramount importance.

Keywords: Mortality, Septic shock, Sepsis, intensive care units, Pediatrics, Critical care

\footnotetext{
* Correspondence: Yousef.altalhi@gmail.com

${ }^{2}$ King Abdullah International Medical Research Centre, Jeddah, Saudi Arabia

${ }^{3}$ King Saud bin Abdulaziz University for Health Sciences, P.O. Box 65362, Jeddah 21556, Saudi Arabia

Full list of author information is available at the end of the article
}

C C The Author(s). 2021 Open Access This article is licensed under a Creative Commons Attribution 4.0 International License, which permits use, sharing, adaptation, distribution and reproduction in any medium or format, as long as you give appropriate credit to the original author(s) and the source, provide a link to the Creative Commons licence, and indicate if changes were made. The images or other third party material in this article are included in the article's Creative Commons licence, unless indicated otherwise in a credit line to the material. If material is not included in the article's Creative Commons licence and your intended use is not permitted by statutory regulation or exceeds the permitted use, you will need to obtain permission directly from the copyright holder. To view a copy of this licence, visit http://creativecommons.org/licenses/by/4.0/ The Creative Commons Public Domain Dedication waiver (http://creativecommons.org/publicdomain/zero/1.0/) applies to the data made available in this article, unless otherwise stated in a credit line to the data. 


\section{Background}

Sepsis is a systemic illness caused by an infectious agent invading the body, which induces the release of inflammatory mediators, resulting in systemic inflammatory response syndrome (SIRS). SIRS is not unique to sepsis. It is a non-specific inflammatory process that can occur after trauma, infection, burns, pancreatitis, and many other diseases [1, 2]. The American College of Chest Physicians/Society of Critical Care Medicine Consensus Conference held in 1991 defined sepsis as SIRS associated with a suspected or proven infection [2, 3]. The International Pediatric Sepsis Consensus Conference accepted this definition for pediatric patients after some modifications. Pediatric SIRS was defined as the presence of $\geq 2$ SIRS criteria, one of which must be abnormal temperature or white cell count. The criteria for vital signs were adjusted according to different pediatric age groups. Suspected or proven infection could be of bacterial, viral, fungal, or rickettsial origin [3].

Sepsis remains a significant cause of morbidity and mortality worldwide. Infectious diseases account for approximately $60 \%$ of deaths in children younger than 5 years old [4]. The 2015 SPROUT Study, which included 128 pediatric intensive care units (PICUs) across 26 countries, showed a sepsis point prevalence of $8.2 \%$, with an overall mortality of 25\%. PICU mortality varied among regions: $21 \%$ in North America, 29\% in Europe, $32 \%$ in Australia/New Zealand, $40 \%$ in Asia, $11 \%$ in South America, and 40\% in Africa [5].

Knowledge regarding the disease is the first step to fully comprehend the impact of sepsis. A limited number of studies have described the epidemiology of pediatric sepsis in Saudi Arabia and the Middle East and North Africa region [6-10]. Understanding the local epidemiology is necessary to develop guidelines that will increase the early identification and improve the management of sepsis. Therefore, this study aimed to identify the incidence of sepsis and septic shock among patients admitted to the PICU of a tertiary center in Saudi Arabia and investigate patients' demographics and risk factors associated with sepsis-related mortality.

\section{Methods}

\section{Study design and participants}

This was a retrospective cohort study conducted at the PICU of King Abdulaziz Medical City-Jeddah (KAMC-J). All pediatric patients admitted to the PICU between January 1, 2013, and December 31, 2017 were identified. The PICU of KAMC-J is a tertiary unit with a 14-bed capacity and an annual admission of approximately 500 patients. Various respiratory and hemodynamic support measures, including extracorporeal membrane oxygenation, are available for use. This study was approved by the Institutional Review Board of King Abdullah
International Medical Research Center prior to commencement.

The study included pediatric patients aged younger than 15 years who had been admitted to the unit during the defined period and met the definition of Sepsis-3. Medical records were reviewed, and all patients were screened and evaluated for sepsis. Patients with missing medical records or incomplete data were excluded.

\section{Study definitions}

In this study, sepsis was diagnosed using the Sepsis-3 definition instead of the SIRS criteria. Sepsis-3 defines sepsis as life-threatening organ dysfunction due to a dysregulated host response to infection using the Pediatric Sequential Organ Assessment (pSOFA) Score (Additional file 1) [11]. This score assesses six organ systems: respiratory, hematological, hepatic, cardiovascular, neurological, and renal. A subscore of 0-4 points is calculated for each component. The pSOFA score was calculated for all patients at and $24 \mathrm{~h}$ after the time infection was first suspected. Patients with confirmed or suspected infection and an increase of $\geq 2$ points in the pSOFA score were diagnosed with sepsis. The lowest value of each subscore during the abovementioned period was used to calculate the pSOFA score.

Septic shock was clinically defined as sepsis with persistent hypotension (requiring vasopressors) in conjunction with a serum lactate level $\geq 2 \mathrm{mmol} / \mathrm{L}$, despite adequate fluid resuscitation [11].

\section{Data collection and analysis}

Variables of interest included demographic data, underlying medical conditions, presence of central lines (either surgical [tunneled] or percutaneous [peripherally inserted central (PIC)]), site of infection, causative organisms, and patient outcome. The primary outcome was 28-day mortality from the date of sepsis onset. The secondary outcome was 7-day mortality from the date of sepsis onset. Patient data were collected from the computerized database and paper files.

Data were analyzed using descriptive statistics to evaluate the study population. Categorical variables were described as total numbers and percentages. Quantitative variables were described as median and interquartile range.

Univariate logistic regression was used to determine the factors associated with an increased likelihood of mortality. The dependent variable was 28-day mortality from the date of sepsis onset. Variables that reached statistical significance in the univariate model subsequently underwent multivariate analysis to estimate the adjusted odds ratios (OR) and 95\% confidence intervals (CI). Statistical analysis was performed using SPSS 
version 26.00 (IBM Corp., Armonk, NY, USA). Statistical significance was set at $p<0.05$.

\section{Results}

During the study period, 2389 patients were admitted to the PICU; 2260 were excluded because they did not meet the sepsis diagnosis criteria and 16 were excluded due to missing data. Ultimately, 113 patients (4.96\%) met the definition of sepsis and were enrolled. Most septic patients (66.3\%) were less than 6 years old, and $47.8 \%$ were female. An acute raise $(>4$ points) in pSOFA score since admission was observed in $45.1 \%$ of patients. The most common primary site of infection was the respiratory tract $(57.5 \%)$. Table 1 details the demographic and clinical characteristics of the patients with sepsis.

Cultures and antigen testings were positive in $67.3 \%$ of patients $(n=76)$, and sepsis was caused by a bacterial pathogen in $60.5 \%(46 / 76)$. However, there was no significant difference in mortality between patients with and without bacterial infections $(11.8 \%(9 / 76)$ vs $15.8 \%(12 / 76)$, respectively; $p=0.651)$. The rate of multi-drug resistant (MDR) bacteria was $21.7 \%$ (10/ 46). No significant difference was found concerning mortality between patients who were infected with MDR organisms $(2.2 \%[1 / 46])$ versus non-MDR organisms $(23.9 \%[11 / 46])(p=0.252)$. Viruses and fungi accounted for 21.2 and $4.4 \%$ of all infections, respectively. The identified organisms among septic patients are shown in Additional file 2.

More than half of the patients $(58.4 \%)$ received antibiotics within $3 \mathrm{~h}$ of admission, and $47.7 \%$ received fluid resuscitation up to $60 \mathrm{ml} / \mathrm{kg}$. Respiratory support in the form of invasive mechanical ventilation was required in $58.5 \%$ of patients with a median duration of 8 days. Approximately half of the patients (50.44\%) were diagnosed with septic shock. The 28-day mortality rate was $23.89 \%$ and the 7 -day mortality rate was $10 \%$. The median duration of PICU stay was 8 days. Table 2 describes the interventions performed for septic patients.

Univariate logistic regression was conducted to identify variables associated with overall mortality (Table 3 ). Only an increase in pSOFA score $>4$, pre-existing PIC line, mechanical ventilation, and PICU length of stay were significantly associated with increased likelihood of mortality $(p<0.05)$. These variables were entered into a multivariate regression analysis to obtain adjusted odds. Consequently, pre-existing PIC line and an increase in pSOFA score $>4$ were significantly associated with increased mortality, with calculated ORs of 9.27 (95\% CI: 1.28-67.29; $p=0.028$ ) and 3.6 (95\% CI: $1.30-9.93 ; p=$ 0.013 ), respectively (Table 4$)$.
Table 1 Demographics and clinical profile of patients admitted to the Pediatric Intensive Care Unit (PICU) with sepsis

\begin{tabular}{|c|c|}
\hline Variables & Septic patients $n=113$ \\
\hline Median age in months (IQR) & $31(86)$ \\
\hline \multicolumn{2}{|l|}{ Age groups (\%) } \\
\hline$\cdot<1$ year & $36(30.9)$ \\
\hline - 1 to $<6$ year & $40(35.4)$ \\
\hline • 6-14 years & $37(32.7)$ \\
\hline Female gender (\%) & $54(47.8)$ \\
\hline \multicolumn{2}{|l|}{ Source of admission (\%) } \\
\hline - Inpatient wards & $62(54.9)$ \\
\hline - Emergency room & $47(41.6)$ \\
\hline - Other local hospitals & $3(2.7)$ \\
\hline - Outpatient department & $1(0.9)$ \\
\hline \multicolumn{2}{|l|}{ Comorbidities (\%) } \\
\hline - None & $28(24.8)$ \\
\hline - Malignancy & $33(29.2)$ \\
\hline - Chronic Respiratory Disease & $8(7.1)$ \\
\hline - Cardiovascular Disease & $5(4.4)$ \\
\hline -Immunodeficiency & $3(2.7)$ \\
\hline - Neuromuscular Disease & $16(14.2)$ \\
\hline - Down Syndrome & $3(2.7)$ \\
\hline - Others & $17(15)$ \\
\hline \multicolumn{2}{|l|}{ Pre-existing central line (\%) } \\
\hline - Percutaneous & $14(12.4)$ \\
\hline - Surgical & $21(18.6)$ \\
\hline \multicolumn{2}{|c|}{ Increase of pSOFA score since admission (\%) } \\
\hline$\cdot \leq 4$ & $62(54.9)$ \\
\hline$\cdot>4$ & $51(45.1)$ \\
\hline \multicolumn{2}{|l|}{ Primary site of infection (\%) } \\
\hline \multicolumn{2}{|l|}{ Bloodstream infection } \\
\hline •- Bacteremia & $30(26.5)$ \\
\hline - -Fungemia & $2(1.8)$ \\
\hline - Respiratory tract & $65(57.5)$ \\
\hline - Central nervous system & $6(5.3)$ \\
\hline - Urinary tract & $3(2.7)$ \\
\hline - Skin and soft tissue & $3(2.7)$ \\
\hline - Others ${ }^{\mathrm{a}}$ & $4(3.5)$ \\
\hline
\end{tabular}

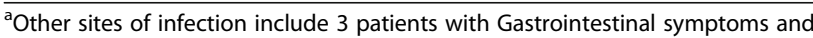
1 patient with arthritis

\section{Discussion}

This study demonstrated a high pediatric sepsis mortality rate, comparable to that of other studies performed in this region $[8,9]$. Risk factors associated with increased mortality were an increase in $P S O F A$ score $>4$ points and the presence of a pre-existing PIC line. Most patients included in the study had associated 
Table 2 Descriptive Statistics of interventions done to patients admitted to the Pediatric Intensive Care Unit (PICU) with sepsis

\begin{tabular}{ll}
\hline Variables & $\boldsymbol{n = 1 1 3}$ \\
\hline Time to Start antibiotics in hours (\%) & \\
• $<3 \mathrm{~h}$ & $66(58.4)$ \\
• $>3 \mathrm{~h}$ (late admistration) & $6(5.3)$ \\
- Not documented & $41(36.3)$ \\
Resuscitation Fluid Volume (\%) & \\
- $0 \mathrm{ml} / \mathrm{kg}$ & $47(41.6)$ \\
- Up to $60 \mathrm{ml} / \mathrm{kg}$ & $54(47.8)$ \\
- $>60 \mathrm{ml} / \mathrm{kg}$ & $12(10.6)$ \\
Median Duration on lonotropic Support in days (IQR) & $1(4)$ \\
Respiratory support (\%) & \\
- Nasal Cannula or Room-air & $30(26.5)$ \\
- Non-invasive & $17(15)$ \\
- Invasive & $66(58.5)$ \\
\hline
\end{tabular}

comorbidities, including malignancies with no association to increased risk of mortality. In addition, delayed administration of antibiotics was not found to increase the risk of mortality.

The reported pediatric sepsis mortality rate varies significantly among different studies, particularly between developed and developing countries. A study conducted by Hassan et al. to assess the feasibility and efficacy of sepsis management guidelines in the PICU revealed a mortality rate of 47.8 and $26.2 \%$, before and after implementing the guidelines, respectively [8]. Another study conducted in a tertiary PICU in Riyadh reported an overall mortality rate of $17.9 \%$ for severe sepsis and septic shock [6]. Moreover, in Egypt, the mortality rate of sepsis has been reported as 28.1 and $8.8 \%$ by Bekhit et al. and El-Mashad et al., respectively [7, 9]. A study performed by the Italian Pediatric Sepsis Study group in Italian PICUs reported a mortality rate of $17.8 \%$ for severe sepsis [12]. Xiao $\mathrm{C}$ et al. carried out an epidemiological study in the main PICU centers in southwest China, reporting a severe sepsis mortality rate of $18.8 \%$ [13]. In 2014, Wang et al. reported a higher rate (34.6\%) for severe sepsis and septic shock among Chinese children [14]. This study's high mortality rate may be related to the use of the pSOFA score instead of the SIRS criteria and thus enrolling higher number of sick patients. Similar to other studies, an increase in the pSOFA score $>4$ points was independently associated with increased risk of mortality. This indicates that a higher pSOFA score suggests increased organ dysfunction and therefore pSOFA score can be a useful predictor of mortality $[11,15]$.

Percutaneous central venous catheters are common sites of bacterial entry and are, thus, associated with an increased risk of central line-associated bloodstream infections [16]. Patients with these lines are at high risk of bloodstream infections due to aggressive hospitalacquired organisms. This type of catheter is usually only required for very sick patients with significant comorbidities, further explaining their association with increased risk of mortality. There was no difference in mortality rate between patients with early versus delayed antibiotic

Table 3 Univariate analysis of risk factors associated with increased mortality among patients admitted to the Pediatric Intensive Care Unit (PICU) with sepsis

\begin{tabular}{|c|c|c|c|}
\hline \multirow[t]{2}{*}{ Variables } & \multicolumn{2}{|l|}{ Outcome } & \multirow{2}{*}{$\begin{array}{l}p \text { - } \\
\text { value }\end{array}$} \\
\hline & $\begin{array}{l}\text { Alive } \\
n=86\end{array}$ & $\begin{array}{l}\text { Dead } \\
n=27\end{array}$ & \\
\hline Age group & & & 0.502 \\
\hline 1 month to $<1$ year & $28(32.6 \%)$ & $8(29.6 \%)$ & \\
\hline 1 year to $<6$ years & $28(32.6 \%)$ & $12(29.6 \%)$ & \\
\hline 6 to 14 years & $30(34.9 \%)$ & $7(25.9 \%)$ & \\
\hline Female Gender & $41(47.7 \%)$ & $13(48.1 \%)$ & 0.996 \\
\hline Increase of pSOFA Score $>4$ since admission & $33(38.4 \%)$ & $18(66.67 \%)$ & 0.012 \\
\hline Pre-existing percutaneous central line (compared to surgical line only) & $6(7 \%)$ & $8(29.6 \%)$ & 0.006 \\
\hline Any morbidity at admission & $61(70.9 \%)$ & $24(89.9)$ & 0.059 \\
\hline Malignancy alone as a co-morbidity & $24(27.9 \%)$ & $9(33.3 \%)$ & 0.589 \\
\hline Septic Shock & $39(45.3 \%)$ & $18(66.7 \%)$ & 0.053 \\
\hline Giving any amount of Resuscitation Fluids & $48(55.8 \%)$ & $18(66.7 \%)$ & 0.318 \\
\hline Ventilation (non-invasive vs. invasive only) & $41(62.1 \%)$ & $25(92.65 \%)$ & 0.020 \\
\hline Late administration of Antibiotics & $4(7.5 \%)$ & $2(7.4 \%)$ & 0.687 \\
\hline Median duration of PICU in days ${ }^{a}$ (IQR) & $8(10)$ & $11(22)$ & 0.031 \\
\hline
\end{tabular}

${ }^{\mathrm{a}}$ Cox \& Snell $\mathrm{R}^{2}=0.042$ 
Table 4 Multivariate analysis of risk factors associated with increased mortality among patients admitted to the Pediatric Intensive Care Unit (PICU) with sepsis

\begin{tabular}{|c|c|c|c|c|c|}
\hline \multirow[t]{2}{*}{ Variables } & \multicolumn{2}{|l|}{ Outcome } & \multirow{2}{*}{$\begin{array}{l}\text { Crude Odds } \\
\text { Ratio } \\
\text { (Cl) }\end{array}$} & \multirow{2}{*}{$\begin{array}{l}\text { Adjusted Odds } \\
\text { Ratio } \\
\text { (Cl) }\end{array}$} & \multirow[t]{2}{*}{$p$-value } \\
\hline & $\begin{array}{l}\text { Alive } \\
n=86\end{array}$ & $\begin{array}{l}\text { Dead } \\
n=27\end{array}$ & & & \\
\hline Increase of pSOFA Score $>4$ since admission & $33(38.4 \%)$ & $18(66.67 \%)$ & $3.21(1.29-7.98)$ & $3.6(1.30-9.93)$ & 0.013 \\
\hline Pre-existing percutaneous central line (compared to surgical line only) & $6(7 \%)$ & $8(29.6 \%)$ & $12.67(2.09-76.70)$ & $9.27(1.28-67.29)$ & 0.028 \\
\hline Non-invasive ventilation (compared to invasive only) & $41(62.1 \%)$ & $25(92.65 \%)$ & $6.034(1.33-27.0)$ & $4.30(0.82-22.62)$ & 0.085 \\
\hline Median duration of PICU stay in days (IQR) & $8(10)$ & $11(22)$ & $1.04(1.003-1.07)$ & $1.02(0.982-1.06)$ & 0.347 \\
\hline
\end{tabular}

administration, which could be attributed to the small number of enrolled patients and the underpowered design of the study. However, a study conducted by Alsadoon et al. in Riyadh, Saudi Arabia reported delayed antibiotic administration was not significantly associated with higher PICU mortality in children diagnosed with severe sepsis [6].

The respiratory tract was the most common primary location of infection, followed by the bloodstream and the central nervous system, as seen in previous studies $[5,13,17]$. The etiologic pathogens of this study were consistent with those of other studies; bacterial infections were the most common, followed by viral and fungal infections $[5,12,13]$. Nonetheless, this study was unable to reveal a relationship between isolated bacteria or MDR organisms and increased risk of mortality.

This study used the age-adapted Sepsis-3 criteria, which uses pSOFA scores rather than the SIRS criteria to identify patients diagnosed with sepsis. The SIRS criteria lack specificity for identifying children with infection at a substantially higher risk of mortality [18]. Studies performed by Schlapbach et al. in Australia and New Zealand and El-Mashad et al. in Egypt - Middle East and North Africa region demonstrated that adapting Sepsis-3 to age-specific criteria performs better than the SIRS criteria in differentiating children with infection at a substantially higher mortality risk. Our findings support the translation of Sepsis-3 into pediatricspecific sepsis definitions and highlight the importance of robust pediatric organ dysfunction characterization [10, 18]. Validation studies regarding age-adapted Sepsis-3 are promising, indicating that Sepsis-3 has the potential to be the future definition for pediatric sepsis [11].

KAMC-J is one of the major tertiary centers in the western region of Saudi Arabia. Thus, most of the children admitted to the pediatric ward have many comorbidities. The pediatric oncology section is the most used in the region, receiving a significant number of referrals; therefore, a high percentage of the children admitted to the PICU have malignancy as a co-morbidity. This explains the high number of patients with comorbidities enrolled in the study. Many studies have suggested patients with malignancies are more likely to die of sepsis than those without malignancies $[12,17]$. Nevertheless, this study found no such association, which is comparable to other studies $[19,20]$. This could be attributed to the early recognition and timely management of such vulnerable patients.

\section{Conclusions}

The incidence of sepsis in KAMC-J is comparable to international data; however, the mortality rate remains high compared to developed countries. Following international guidelines for central line insertion and maintenance is of paramount importance. Implementation of a national database will help conduct large-scale studies to determine areas of weakness regarding the diagnosis of sepsis and, therefore, improve pediatric sepsis outcomes.

\section{Limitations}

The study was limited by its retrospective design and the relatively small number of patients from a single center. Some of the data concerning the timing of administration of the antibiotics was missing in some of the charts, which probably affected the univariate analysis of the variable. The limited number in the sub-groups of the multivariate regression underpowered the adjusted odds ration of the variables included in the model.

\section{Abbreviations}

PICU: Pediatric intensive care unit; KAMC-J: King Abdulaziz Medical CityJeddah; pSOFA: Pediatric sequential organ failure assessment score; PIC line: Peripherally inserted central line; OR: Odds ratio; Cl: Confidence interval; MDR: Multi-drug resistance

\section{Supplementary Information}

The online version contains supplementary material available at https://doi. org/10.1186/s12887-021-02686-0.

\section{Additional file 1.}

Additional file 2 


\section{Authors' contributions}

All authors contributed majorly to the writing of the manuscript. Maha Azzam designed the study. MH and MS collected the data. YA analyzed and interpreted the data. All authors read and approved the final manuscript.

\section{Funding}

This study received no financial support from in local or international institutions.

\section{Availability of data and materials}

The datasets used and/or analyzed during the current study are available from the corresponding author on reasonable request.

\section{Declarations}

\section{Ethics approval and consent to participate}

Patients' privacy and confidentiality were completely preserved. No personal identifier or information was collected or stored. All methods were performed in accordance with the relevant guidelines and regulations. The requirement for informed consent was waived by the ethical committee given the retrospective study design. This study was approved by the Institutional Review Board of King Abdullah International Research Center.

\section{Consent for publication}

Not applicable.

\section{Competing interests}

The authors declare that they have no competing interests.

\section{Author details}

'Department of Pediatrics, King Abdulaziz Medical City, P.O. Box 65362, Jeddah 21556, Saudi Arabia. ${ }^{2}$ King Abdullah International Medical Research Centre, Jeddah, Saudi Arabia. ${ }^{3}$ King Saud bin Abdulaziz University for Health Sciences, P.O. Box 65362, Jeddah 21556, Saudi Arabia.

Received: 3 December 2020 Accepted: 22 April 2021

Published online: 07 May 2021

\section{References}

1. Bone RC, Sprung CL, Sibbald WJ. Definitions for sepsis and organ failure. Crit Care Med. 1992;20(6):724-6. https://doi.org/10.1097/00003246-19920600000002.

2. Bone RC, Balk RA, Cerra FB, Dellinger RP, Fein AM, Knaus WA, et al. Definitions for sepsis and organ failure and guidelines for the use of innovative therapies in sepsis. The ACCP/SCCM consensus conference committee. American College of Chest Physicians/Society of Critical Care Medicine. Chest. 1992; 101(6):1644-55. https://doi.org/10.1378/chest.101.6.1644.

3. Goldstein B, Giroir B, Randolph A. International consensus conference on pediatric S: international pediatric sepsis consensus conference: definitions for sepsis and organ dysfunction in pediatrics. Pediatr Crit Care Med. 2005; 6(1):2-8. https://doi.org/10.1097/01.PCC.0000149131.72248.E6.

4. Liu L, Johnson HL, Cousens S, Perin J, Scott S, Lawn JE, et al. Global, regional, and national causes of child mortality: an updated systematic analysis for 2010 with time trends since 2000. Lancet. 2012;379(9832):215161. https://doi.org/10.1016/S0140-6736(12)60560-1.

5. Weiss SL, Fitzgerald JC, Pappachan J, Wheeler D, Jaramillo-Bustamante JC, Salloo A, et al. Global epidemiology of pediatric severe sepsis: the sepsis prevalence, outcomes, and therapies study. Am J Respir Crit Care Med. 2015;191(10):1147-57. https://doi.org/10.1164/rccm.201412-2323OC.

6. Alsadoon A, Alhamwah M, Alomar B, Alsubaiel S, Almutairi AF, Vishwakarma RK, et al. Association of Antibiotics Administration Timing with Mortality in children with Sepsis in a tertiary Care Hospital of a Developing Country. Front Pediatr. 2020;8:566. https://doi.org/10.3389/fped.2020.00566.

7. Bekhit Oel S, Algameel AA, Eldash HH. Application of pediatric index of mortality version 2: score in pediatric intensive care unit in an African developing country. Pan Afr Med J. 2014;17:185.

8. Hasan GM, Al-Eyadhy AA, Temsah MA, Al-Haboob AA, Alkhateeb MA, AlSohime F. Feasibility and efficacy of sepsis management guidelines in a pediatric intensive care unit in Saudi Arabia: a quality improvement initiative. Int J Qual Health Care. 2018;30(8):587-93. https://doi.org/10.1093/ intghc/mzy077.
9. Mohamed El-Mashad G, Said El-Mekkawy M, Helmy Zayan M. Paediatric sequential organ failure assessment (pSOFA) score: a new mortality prediction score in the paediatric intensive care unit. An Pediatr (Barc). 2020; 92(5):277-85. https://doi.org/10.1016/.janpedi.2019.05.018.

10. Sarah Alseneidi FA, Alalwan M, Aleyadhy A. Outcome of sever sepsis in pediatric intensive care at a saudi tertiary hospital: observational study. In: International Conference on General Practice \& Hospital Management: 2016. Dubai: Journal of General Practice; 2016.

11. Matics TJ, Sanchez-Pinto LN. Adaptation and validation of a pediatric sequential organ failure assessment score and evaluation of the Sepsis-3 definitions in critically ill children. JAMA Pediatr. 2017;171(10):e172352. https://doi.org/10.1001/jamapediatrics.2017.2352.

12. Wolfler A, Silvani P, Musicco M, Antonelli M, Salvo I. Italian pediatric Sepsis study g: incidence of and mortality due to sepsis, severe sepsis and septic shock in Italian pediatric intensive care units: a prospective national survey. Intensive Care Med. 2008;34(9):1690-7. https://doi.org/10.1007/s00134008-1148-y.

13. Xiao C, Wang S, Fang F, Xu F, Xiao S, Li B, et al. Epidemiology of pediatric severe Sepsis in Main PICU centers in Southwest China. Pediatr Crit Care Med. 2019;20(12):1118-25. https://doi.org/10.1097/PCC.0000000000002079.

14. Wang Y, Sun B, Yue H, Lin X, Li B, Yang X, et al. An epidemiologic survey of pediatric sepsis in regional hospitals in China. Pediatr Crit Care Med. 2014; 15(9):814-20. https://doi.org/10.1097/PCC.0000000000000247.

15. Lalitha A, Satish J, Reddy M, Ghosh S, George J, Pujari C. Sequential organ failure assessment (SOFA) score as a predictor of outcome in Sepsis in pediatric intensive care unit. J Pediatr Intensive Care. 2021;10(02):110-17.

16. Marschall J, Mermel LA, Fakih M, Hadaway L, Kallen A, O'Grady NP, et al. Strategies to prevent central line-associated bloodstream infections in acute care hospitals: 2014 update. Infect Control Hosp Epidemiol. 2014;35(S2):S89S107. https://doi.org/10.1017/S0899823X00193870.

17. Watson RS, Carcillo JA, Linde-Zwirble WT, Clermont G, Lidicker J, Angus DC. The epidemiology of severe sepsis in children in the United States. Am J Respir Crit Care Med. 2003;167(5):695-701. https://doi.org/10.1164/rccm.2002 07-6820C.

18. Schlapbach LJ, Straney L, Bellomo R, MacLaren G, Pilcher D. Prognostic accuracy of age-adapted SOFA, SIRS, PELOD-2, and qSOFA for in-hospital mortality among children with suspected infection admitted to the intensive care unit. Intensive Care Med. 2018;44(2):179-88. https://doi.org/1 0.1007/500134-017-5021-8.

19. Pound CM, Johnston DL, Armstrong R, Gaboury I, Menon K. The morbidity and mortality of pediatric oncology patients presenting to the intensive care unit with septic shock. Pediatr Blood Cancer. 2008;51(5):584-8. https:// doi.org/10.1002/pbc.21670.

20. Fiser RT, West NK, Bush AJ, Sillos EM, Schmidt JE, Tamburro RF. Outcome of severe sepsis in pediatric oncology patients. Pediatr Crit Care Med. 2005; 6(5):531-6. https://doi.org/10.1097/01.PCC.0000165560.90814.59.

\section{Publisher's Note}

Springer Nature remains neutral with regard to jurisdictional claims in published maps and institutional affiliations.

Ready to submit your research? Choose BMC and benefit from:

- fast, convenient online submission

- thorough peer review by experienced researchers in your field

- rapid publication on acceptance

- support for research data, including large and complex data types

- gold Open Access which fosters wider collaboration and increased citations

- maximum visibility for your research: over $100 \mathrm{M}$ website views per year

At BMC, research is always in progress.

Learn more biomedcentral.com/submissions 